\title{
The Limitation and Improvement of GATT1994 Environmental Exception Clauses
}

\author{
Jiesi Fu ${ }^{1, a, *, \dagger}$ Jieshen $\mathrm{Li}^{2, b, \dagger}$ Yulin $\mathrm{Wei}^{3, \mathrm{c}, \dagger}$ \\ ${ }^{1}$ The Chinese University of Hong Kong, Hong Kong, China \\ ${ }^{2}$ Kunming No.10 CBCIS high school, Kunming, Yunnan, China \\ ${ }^{3}$ Gansu University of Political Science and Law, Lanzhou, Gansu, China \\ *Corresponding author.Email: ${ }^{a} 1155146737 @$ link.cuhk.edu.hk, ${ }^{b} 13518733907 @$ qq.com \\ ${ }^{c} 1094464026 @ q q . c o m$,
}

${ }^{t}$ These authors contributed equally.

\begin{abstract}
WTO is an international organization that holds the main value orientation of free trade. To balance with other social values, WTO has formulated exception clauses. As environmental issues have increasingly become a topic of concern to the international society, the value of Environmental Exception Clauses (EEC) has become more prominent. However, the standardization and judicial practice of this clause limits its effectiveness. This article studies the defects and causes of those issues of the EEC by using the methods of case analysis, system analysis, and norm analysis. It holds that, clarifying the standard of use, improving the government information disclosure system and revising the WTO regulations can effectively enhance the role of Environmental Exception Clauses in practice.
\end{abstract}

Keywords: Environmental Exception Clauses (EEC), WTO, GATT 1994, Panel Report

\section{INTRODUCTION}

Under the trade of globalization, WTO, as a professional recognition to protect free trade, provides member states a great variety of rights and obligations. General Agreement of Tariffs and Trade (GATT), a multilateral international agreement concluded by member states of WTO, aims to promote international trade by reducing tariffs and other trade barriers, eliminating differential treatment in international trade. These days, the topic of "trade and the environment" seems to be sprouting up everywhere. In thinking about whether the GATT needs to be "greened", as some environmentalists have urged, one might start by exploring the environmental provisions currently in the GATT. Article XX (General Exceptions) states that: "Subject to the requirement that such measures are not applied in a manner which would constitute a means of arbitrary or unjustifiable discrimination between countries where the same conditions prevail, or a disguised restriction on international trade, nothing in this Agreement shall be construed to prevent the adoption or enforcement by any contracting party of measures: (b) necessary to protect humans, animals, or plant life or health;

(g) relating to the conservation of exhaustible natural resources if such measures are made effective in conjunction with restrictions on domestic production or consumption;"

As the concentration of environmental protection has grown, EEC should gradually play a greater role, with data from 2016 to 2021 panel reports showing that few member states in which the clause has been applied in the past two decades won. Therefore, after researching the Brazilian tax case and China Rare Earths case, this essay notices some problems of the WTO panel of experts and the appellate body, also indicating that there are issues in the content of the environmental exception clause and in judicial practice. From a content point of view, the environmental exception clause is not clear. From a judicial point of view, the expert group failed to balance the environmental exception clause and the principle of free trade. At the same time, the original essence of free trade is also inconsistent with the trend of environmental protection. This essay will mainly focus on the issues of regulation itself and judicial application. 


\section{LIMITATIONS OF ENVIRONMENTAL EXCEPTION CLAUSES AND THE LEGAL REASONS}

Under the background of environmental problems, which are attracting increasing attention, the application of environmental exception clauses in GATT 1994 among international trade shows a growing trend. However, there are still many shortcomings in the regulation itself and in judicial practice. A detailed analysis from the perspective of the integrity of the standard, the relationship between the environmental exceptions and the principle of free trade, and the disadvantage of the core essence of free trade principles in GATT will provide a sufficient basis for solving problems.

\subsection{Limitations On The Norm of Environmental Exception Clauses}

\subsection{1. "Ambiguous Meaning of The Environmental Exception Clauses" Issues}

GATT is the consequence of negotiation among member countries. Therefore, the environmental exception clauses in GATT XX are ambiguous so that articles can be explained differently in cases to keep the balance between countries. However, the result of blurry articles is that the essence of articles may be contradictory with other articles. For example, there is a conflict between "Environmental Exception Clauses" and "Agreement of Technical Barriers to Trade": In chapeau of GATT XX, an element of the EEC, WTO need to judge whether membership countries have "the same conditions prevailed" with another one in a case, that means WTO has the right to judge the domestic policy completely to assess whether "the same conditions prevail". However, in agreements of technical trade barriers, WTO sent the assessment rights of domestic policies back to membership countries, expressing like "At the level of what they suppose appropriate." In cases judgment, when finding out whether membership countries formed environmental discrimination with other countries, it is important to take technical factors into considerations. Therefore the explaining of domestic policies exerted influences on the judgment. However, the conflict between the environmental exception clauses and technical trade barriers may lead to different explaining policies.

\subsection{2. "Designed" Issues}

In terms of the judgment of GATT XX (b), according to cases in GATT, there are two steps to judge whether a case is subject to environmental exception clauses: One, checking whether the challenged measures are "designed" to protect human rights and life. Two, checking whether the challenged measures are "necessary" to protect human rights and life [1]. Here is the detailed analysis.

When analyzing the "designed" step aforementioned, there are still two sub-steps: First, sub-step is judging whether the panel "enjoys a margin of discretion in assessing the value of the evidence, and the weight to be ascribed to that evidence, including the use of experts." if the measure obeyed the principle, then checking second sub-step: To examine whether the policy underlying the measure aims to reduce such risk [2].

\subsubsection{Judging Step 1}

Analyzing the meaning of sub-step one, it demonstrated that the rationality for the panel to judge the legal efficiency is under doubt because here is criticism of the GATT panel processes in that they fail to make provisions for the transmittal of arguments, information, and evidence from a variety of interested groups. Besides, The judgments of evidences are mainly a scientific problem, meaning that scientists should contribute more to determine the powers of evidences. However, the compositions of judgments are legal experts, and they do not have enough scientific knowledge to judge the power of evidences.

\subsubsection{Judging Step 2}

Under the contents aforementioned, in this connection, it is clearly established that Members have the right to determine the level of protection that they deem appropriate". However, environmental protection is relevant to domestic interests and the whole human being's interests. Therefore, if there is some serious environmental pollution, the International community should not overlook it. Besides, to protect domestic markets, some undeveloped countries form trade barriers to restrict foreign goods in the name of environmental protections. It not only did not assist environmental protection, but also hinder trade freedom [3].

\subsection{3. "Necessary" Problems}

Talking about the "necessary" problem, two key questions are: what is the standard of "necessary"? What should be taken into account when judging whether a policy is consistent with the standard?

To cope with the first question, WTO has given explanations in case analysis. In US-Alcoholic and Malt Beverages in 1989, the panel argued that no other more WTO-compatible or less-restrictive alternative was reasonably available to pursue the desired policy goal [4]. Besides, although the measures are expected to be employed, if it is inconsistent with other provisions, the contracting party cannot prove it as the "necessary" measure. 
As for the second problem, WTO has argued that coordinating benefits, including public interests, economic interests, and the effects of the policy, is the main consideration of "necessary".

Theoretically, the assessment system is crystal-clear and keeping the balance between different benefits. However, it was not enacted well in reality [5].

\subsection{4. "This Agreement" Issue In The Chapeau of Article XX of The GATT 1994}

Still, in the China-rare earth cases, China argues that the terms "nothing in this Agreement" in the chapeau of Article XX of the GATT 1994 do not exclude the availability of Article XX to defend a violation of Paragraph 11.3 of China's Accession Protocol [6]. However, the panel and appellate body insist that the reference to this "agreement" suggests that the exceptions relate only to GATT 1994 and not to other agreements. The problem is whether any provisions of post-1994 accession protocols should be included as a legally integral part of GATT 1994? In other words, what does the term "this agreement" contain? Whether the exceptions under Article XX of the GATT 1994 can be available to excuse violations of "WTO-plus" provisions contained in post-1994 accession protocols?

In fact, WTO failed to give a clear answer. Consequently, the exceptions under Article XX of the GATT 1994 are also available to excuse violations of what it labels intrinsically GATT-related "WTO-plus" provisions contained in post-1994 accession protocols.

\subsection{Issues: Conflicts Between The chapeau of Environmental Exception Clauses and the Free trade Principle}

Under the tide of economic globalization, every country pursues free trade to the maximum extent for economic development. Certain international trades should be limited or prohibited because of environmental protection. There is a growing sense of urgency about environmental issues. At the same time, WTO still holds misconceptions that "trade liberalization must be promoted at whatever cost including forcing Members to endure environmental degradation and the exhaustion of their scarce natural resources" [7]. The general exceptions, especially environmental ones, should be welcomed to play a positive and constructive role in trade. It is inevitable to have privatized comfort blanket when a member country formulates and implements an external policy. However, if the environmental benefit brought by this policy outweigh that of trade protectionism, Members have always had the right to promote fundamental societal interests besides trade liberalization under the WTO Agreement [8], and panels need to support them.
As it is said in the chapeau of article XX from GATT 1994: "subject to the requirement that such measures are not applied in a manner which constitutes a means of arbitrary or unjustifiable discrimination between countries where the same conditions prevail, or a disguised restriction on the international trade, nothing in this Agreement shall be construed to prevent the adoption or enforcement by any contracting party of measures."

In practice, whether the policy constitutes the terms 'arbitrary or unjustifiable discrimination and 'disguised restriction on the international trade' have been reviewed strictly by the panel in every specific case. Otherwise, article XX may be abused by some member states to display trade protectionism. This is the right thing to do, but WTO does not specify the concept and application of these terms, so that it conflicts with the principle of free trade.

\subsubsection{The Necessity To Concentrate On The Chapeau}

The chapeau enables member states to have their substantive rights, that is, to protect public health and the environment, but to ensure that their own economic measures will not cause trade protectionism.

\subsubsection{The Meaning Of The Chapeau}

\subsubsection{Arbitrary Or Unjustifiable Discrimination}

According to this term, its meaning contains: the relevant measures don't constitute arbitrary or justifiable discrimination, and if the measure constitutes the discrimination, the panel needs to judge whether it is arbitrary or unjustifiable or not.

In the WTO precedents, it can be noticed that to judge whether it is arbitrary or unjustifiable or not is to review whether the measures for other countries aim to themselves. But it is not a well-rounded mean. If the invoking party just requires countries to be comparable in effectiveness with the domestic measures, such a requirement does not constitute arbitrary discrimination.

\subsubsection{Disguised Restriction On The International} Trade

In the practice of the GATT Dispute Settlement Body(DSB) practice, the panel used to use 'whether the measure was announced' as a criterion for restricting trade in a disguised form. It must be admitted that there is a certain reason for this. It is possible to supervise the performance of transparency obligations by member states in trade, but this is obviously not comprehensive, and only some restrictive measures can be excluded. Member states have likely announced measures, but 
their measures still constitute disguised restrictions on trade.

However, this issue has not been explained in detail in the cases involving the chapeau of Article XX during the WTO period.

\subsubsection{The Presentation Formats Of Conflict Between Environmental Exceptions And Trade Liberalization}

In WTO law, it formulates a principle of mostfavored-nation(MFN) and some regulations about reducing taxes and charges levied on imports and exports, all of which constitute the core principles of free trade developing an integrated trading system. To be more specific, the MFN principle refers to a contracting state now and in the future, for any state to give any third country trade, tariffs, shipping, the civil and legal status of concessions, and exemptions, which are also given to countries. i.e. all the contracting states re-entitled not to be discriminated against. To illustrate, this principle can be applied to any import-related taxes and relevant regulations under GATT. Based on this, international trade is relatively easy to carry out. The Member States with different environmental protection capabilities may become eligible trade entities, thereby posing potential environmental threats to the importing country. Inevitably, this would lead to conflicts about environmental protection. At the same time, GATT XX (b) (g), i.e. the EEC, provide an exception for member states to reduce the environmental harm of specific imported and exported products, such as through setting tariff and higher export taxes, which would clearly exert beneficial impact on the member states' environment. However, if imposing environmental taxes or tariffs, it is easy to be considered to protect domestic production, resulting in trade disputes.

Therefore, trade conflicts related to the environment have emerged one after another in practice. Many countries have brought disputes to the WTO Dispute Settlement Body(DSB) for help, such as the Brazilian tire retreading case in 2005, the Chinese raw materials case in 2010, and the Indonesian chicken product case in 2017, and much more. Most of the defendants who used EEC as their defenses lost the cases.

Taking the case of the China Rare Earth dispute (WT/DS431/R, WT/DS432/R, WT/DS433/R) in 2012 as an example. China is one of the countries with the largest rare earth resources in the world.

To protect the ecological environment and strategic resources, China has implemented a series of policies restricting the export of rare earth and other raw materials. This has caused dissatisfaction from the United States, the European Union, Japan, and other countries.
They believe that in respect of export duties, the measures are inconsistent with China's obligations under Paragraph 11.3 of Part I of the Accession Protocol [4]. Furthermore, China uses GATT XX $(\mathrm{b})(\mathrm{g})$ as its defense since the country has sovereignty over natural resources. It has the right to formulate trade management measures, and that those measures to protect the rare resources from improper consumption could help achieve the goal of global sustainable development. Additionally, the experts in WTO believe that China's measures on rare earth and other resources fail to meet the requirements of Article XX (b) $(\mathrm{g})$. What's more, there are no relevant measures to prove that they meet the Chapeau of Article XX. In the Panel's view, China has not demonstrated that the distortion created by applying its export quota system is merely incidental to its conservation policy considerations [9]. In brief words, they actually are unreasonable discrimination or disguised restrictions on international trade. However, it turns out that's not the case. In fact, China's environment suffers a lot because of the lack of pricing rights for rare earths and domestic rare earth supply market chaos, unfair competition for prices, and the lack of relatively mature environmental protection and mining regulations. Such measures are more beneficial for the environment. Similarly, the WTO also opposed the US defense for the same reason in the US Sea Turtle and Shrimp Case.

It can be clearly seen that when dealing with conflicts between free trade and environmental protection, the WTO is more inclined to protect the former. Nowadays, environmental problems like global warming, the transboundary movement and spread of toxic and hazardous chemicals and waste, the sharp decline of biodiversity, and marine pollution have become increasingly serious. Therefore, the WTO, as a global body, should put more emphasis on social responsibility like environmental protection responsibility. This way can help WTO achieve the goals of raising people's standard of living and developing an integrated, more viable, and durable trading system.

\subsection{The Disadvantage Of The Core Essence Of Free Trade Principles In GATT}

To observe the limitations of the Free Trade principle, the Marrakesh agreement is critical because it represents the altering of Free-trade principles.

\subsubsection{Before Marrakesh}

Before the Marrakesh agreement, to protect the environment, GATT has been asked to make some contributions to UNCED (United Nation Conference on Environment and Trade). As a result, GATT wrote a research report on industrial pollution and trade. Later on, GATT established EMIT (Environment Measures 
and International Trade) group, which dedicated to solving environmental issues. In addition, it is also open to GATT member states only. However, this group has been stagnant for 20 years after its establishment in 1971 and was not reactivated until 1992. And in these 20 years, two big events happened. The first one is the concept of the Free trade principle-One of the WTO principle of the trading system begins to emerge during the 1980s. And the second one is the dispute between America and Mexico about the US ban on tuna imports from Mexico. The nets to catch tuna will incidentally hurt dolphins. Because the US tried to adopt the EEC, but the Panel did not support it, the Panel of GATT has been criticized by the international environmental protection groups.

From the introduction abovementioned, it can be seen that GATT pays more attention to trade issues in early periods, and promoting economic benefits behind is the policy-making priority. However, with global people feeling the negative impressions of environmental pollution and biological damages, GATT and WTO are also affected by the environmentalprotection waves. Therefore, when they reform legislation and institutions, merely sticking to policy priorities in the 1970s or 1980s cannot meet the needs of present concerns.

\subsubsection{After Marrakesh}

With the establishment of the Marrakesh agreement in 1994, It can be seen that GATT, or the soon to be established WTO, gradually changed the essence of free trade principle, "allowing for the optimal use of the world's resources and being consistent with their respective needs and concerns at different levels", and added contents about environmental protection, like "sustainable development, seeking both to protect and preserve the environment".

However, The terms "consistent with their respective needs and concerns at different levels of economic development." representing a huge bulk of economic development needs, and "Protecting Environment, Sustainable Development" representing the need to guarding environmental benefits, even sacrificing short-term developing benefits to some extents, are in contradictory.

\section{CONSTRUCTION OF A COMPLETED LEGAL SYSTEM OF THE ENVIRONMENTAL EXCEPTION CLAUSES}

\subsection{Resume The Theoretical Essence Of The "Free Trade Principle"}

\section{—Can WTO talk about trade liberalization under}

the premise of destroying the environment?

Countries are striving to seek trade liberalization, while WTO believes that the core of free trade is reducing various trade barriers to improve human living standards and expand the production of and trade in goods and services while allowing for the optimal use of the world's resources in accordance with the objective of sustainable development. Here is the original theoretical essence of trade liberalization.

However, the essence of Free Trade fails to be implemented thoroughly because rights of power and voice of free trade are in the hands of major nations, and the competitions between them impose adverse effects on it. Big powers take advantage of the superior and unreasonable old international economic order of powers in WTO activities. On the contrary, the developing countries mainly export primary products based on the intensive and even predatory development of their domestic resources and pay a high price for ecological destruction and environmental pollution. However, developed countries purchase primary products at lower market prices without considering the value of environmental resources.

Secondly, a new round of environmental damage will bring new threats to environmental security. Some developed countries have transferred polluting and environmentally harmful industries, equipment, products, and hazardous waste to developing countries for a long time. With the liberalization of international trade and economic globalization, the possibility of developing countries suffering from environmental damage has greatly increased.

Nevertheless, with the rise of developing countries, the core of trade freedom should rehabilitate the original meaning and follow the trend of environmental protection. The United Nations Secretary-General António Guterres recently issued a statement stating that to achieve the core goal of controlling temperature rise in the Paris Agreement, the world urgently needs all members of the Group of Twenty (G20). To make "clear and unambiguous promise." Guterres also urged developed countries to fulfill their commitments to support developing countries in addressing climate change. He appealed to the Group of Seven and other developed countries to provide a series of support to developing countries, including giving 100 billion U.S. dollars per year to developing countries. So, investment in climate adaptation and resilience-building accounted for at least $50 \%$ of the total climate financing and aligned the climate investment portfolios of public and multilateral development banks with the needs of developing countries.

Therefore, as an international body, WTO can't talk about trade liberalization under the premise of 
destroying the environment. WTO should play an essential role in balancing international free trade and environmental protection. This essay will provide two perspectives for solving the problem.

\subsubsection{WTO Should Continually Improve International Law.}

Firstly, WTO needs to give developed countries more international obligations by establishing some new agreements. According to the principle of common but differentiated in environmental law, all countries are responsible for protecting the global environment. In contrast, developed countries should be given more obligations and responsibilities in preserving the environment. On the one hand, developed countries should control the production and discharge of certain substances that have a major impact on the environment and take the lead in adopting relevant measures, appropriately granting developing countries a certain grace period. On the other hand, developed countries should provide additional funding and capital to developing countries in terms of technology.

Secondly, the WTO should seek the coordination of product standards. The level of product standards indicates whether a country has priority in environmental protection or trade-in its institutional choice. Prioritizing environmental protection will hinder trade, and prioritizing trade will reduce the environmental protection level of certain countries. Therefore, the coordination of product standards is also particularly important on a global scale.

Thirdly, WTO can improve the dispute settlement mechanism. The conflicts between the environment and trade originate from the conflicts of interests between developed and developing countries. They will not disappear in a short period. At this stage, once a conflict occurs, there still needs a relatively complete comedy mechanism. That's why this essay hopes to find out a solution through the study of GATT XX by clarifying relevant professional terms and essence (in 3.2). Finally, achieve global common prosperity and sustainable development.

\subsubsection{WTO Needs To Change The Old And Unequal International Economic Order And Establish A New And Fair International Economic Order.}

Only by establishing a new and fair international economic order, founding global partnership, working together to adjust the relationship between the current multilateral international trading system and multilateral environmental treaties can the coordination of trade and environmental protection be fulfilled. Therefore, developed countries should extend a helping hand from the aspects of technology, capital, manpower, etc. The dual role of internal and external factors in developing countries can quickly get out of the state of subsistence economy and improve their ability to participate in international competition. At the same time, developing countries should actively participate in international conferences on trade and environmental issues and strive to work with developed countries to formulate fair and reasonable environmental trade policies and measures, and ensure their transparency, so as not to create new trade barriers or be detrimental to their own environmental protection.

\subsection{Improve The Content Of GATT Environmental Exception Clauses}

International environment and trade disputes increasingly arouse great attention around the world. The number of cases and types is unprecedented. There is another important reason here: the rules issues that all parties in the dispute invoke. The ambiguity and incoordination are the essential factors for conflicts, which are particularly obvious in the process of applying environmental exception clauses. As the content mentioned in 2.1.1, the terms "necessary", "this agreement" of GATT 1994 XX (b) are not that clear for application. Therefore, the measures should be improved as follows:

\subsubsection{Add Detailed Provisions On Applicable Standards In The Clauses}

Firstly, in terms of the issue of "necessary", when facing massive and different cases that involve environmental exception clauses, the WTO already gave the procedures of analyzing and scope of "necessary" in Article XX of GATT 1994 with some exemplar cases , and yet, although the basic process of analyzing for those case are the same, some of the steps are different from one another due to the different Panels, which lead the explanation of the clause is unclear. So the WTO should define in detail the meaning of "necessary" to make it clearer for understanding and explaining, and affirm a specific procedure for the Panels. At the same time, international environmental protection organizations should be allowed to participate in dispute settlement, such as The Nature Conservancy (TNC), Center for International Environmental Law, World Wild Fund for Nature, and other non-governmental organizations. Because of their deep expertise in related environmental protection fields, WTO should give them more rights regarding fact determination.

Secondly, when it comes to the issues about the chapeau of GATT $1994 \mathrm{XX}$, the problems "this agreement", whether international environmental agreements or GATT-related agreements can be used as 
sources of interpretation and judicial practice WTO, is still controversial. This paper advocated that WTO should apply GATT 1994 and other related agreements in accordance with the customary interpretation rules for dispute settlement in international law.

Among them, the customary interpretation rules can refer to Article 38 of the Statute of the International Court of Justice: " 1 . The court, whose function is to decide in accordance with international law such disputes as are submitted to it, shall apply: a. international conventions, whether general or particular, establishing rules expressly recognized by the contesting states; b.international customs, as evidence of a general practice accepted as law; c.the general principles of law recognized by civilized nations; $d$. subject to the provision of Article 59, judicial decisions and the teachings of the most highly qualified publicists of the various nations, as subsidiary means for the determination of rules of law. 2. This provision shall not prejudice the power of the Court to decide a case ex aequo et bono if the parties agree thereto." Besides, international disputes refer to disputes and confrontations between two or more recognized subjects of international law, mainly between countries, due to conflicts of legal rights or political interests $[10,11]$.

Therefore, the international disputes of interests arising from the freedom of trade and environmental protection between the WTO member states should be subject to the general rules applicable to international law.

\subsubsection{Enhancing Governmental Information Disclosure System}

As mentioned, in environmental-related disputes, when citing GATT XX chapeau, the presenting measures to judge whether a policy is a "disguised restriction on international trade" is to check whether the policy was announced.

Inspired by the word "announced", meaning to make something known, when making environmental policies possibly having negative effects on foreign investments and goods transactions, membership governments should implement and improve information disclosure systems, and a critical step is making "Risks warning lists"(RWL). The contents in the list include potential administrative and judicial measures for membership nations, possible affected foreign industries, enterprises, investments, market ratios, and periods. There are two purposes: One is to assist foreign businesses and investors in knowing the perspective environmental policies host countries implement and then making rational decisions. When WTO deals with disputes about the environmental exception, the explicit measures guide the panel and DSB, decreasing possible risks that WTO member states exert influences on the judgments.

In reality, setting RWL can not only be used on coping with "disguised restriction". It is also important to reform the old-fashioned environmental exception clauses born in 1947 and never be changed. Borrowing "Systematic Interpretation", putting RWL in GATT XX (b) is rational. Hence GATT XX (b) can be altered like this:

necessary to protect human life... but the precondition is that member government has published "risks warning lists", including potential administrative and judicial measures for membership nations, possibly affected industries, foreign enterprises, investments, market ratios, and periods.

\section{CONCLUSION}

In recent years, since the international structure has been affected by many factors, it has gradually changed. The fragmentation of international economic and trade rules may even lead to a partial collapse of the international legal system. Especially since 2020, the epidemic of COVID-19 has further intensified the contradictions. What's more, the WTO Appellate Body is currently in a state of suspension, and the functions that WTO can perform are restricted.

However, as a manifestation of WTO's environmental protection policy, EEC reflects the problems and potentially effective solutions, such as improving ruling standards and promoting transparency in government information. It can provide ideal examples for international environmental protection and more possibilities for environmental consideration during international trade.

\section{REFERENCES}

[1] Brazil - Certain Measures Concerning Taxation and Charges panel report-P233 7.858.

[2] Brazil - Certain Measures Concerning Taxation and Charges panel report panel report-P234 7.859.

[3] Juliya Arbisman, Navigating sustainable development in the WTO, Int. T.L.R. 2016, 22(2), 49-52.

[4] United States - Measures Affecting Alcoholic and Malt Beverages panel report-P39 3.67.

[5] Dale Arthur Oesterle, Just say "I don't know": a recommendation for WTO panels dealing with environmental regulations, Env. L. Rev. 2001, 3(2), 113-130.

[6] China-rare earth panel report-P62 7.100.

[7] China-rare earth panel report-P63 7.105. 
[8] China-rare earth panel report-P63 7.106.

[9] Paragraph 11.3 of Part I of the Accession Protocol: China shall eliminate all taxes and charges applied to exports unless specifically provided for in Annex 6 of this Protocol or applied in conformity with the provisions of Article VIII of the GATT 1994).

[10] AGREEMENT ESTABLISHING THE WORLD TRADE ORGANIZATION, page 9, The Parties to this Agreement, Paragraph 1, line 1-7, The principle and establishment of Word Trade Organization System. DOL: https://www.wto.org/english/docs_e/legal_e/04wto_e.ht.

[11] Mavrommatis Palestine Concessions Case, PCIJ, Serious A, No.2(1924), p.11. 